\title{
Sobre a gramática moral do crime: A mobilização de justificativas e acusações em homicídios na Zona Leste de Belo Horizonte
}

\section{Rafael Lacerda Silveira Rocha}

Universidade Federal de Minas Gerais, Belo Horizonte, MG, Brasil

O artigo visa examinar os discursos e elementos simbólicos mobilizados por atores inseridos no "mundo do crime" para justificar ou condenar assassinatos na Zona Leste de Belo Horizonte, área periférica da cidade. A pesquisa, baseada na análise de inquéritos policiais e entrevistas, se concentrou em investigar o modo como esses atores fazem uso de uma gramática moral como forma de justificação da legitimidade de assassinatos ou os considerar injustos, o que configura ofensa a ser reparada por meio de retaliações violentas.

Palavras-chave: homicídios, guerra, moral, retaliação, Belo Horizonte
On the Moral Grammar of Crime: The Mobilization of Justifications and Accusations in Homicides in Belo Horizonte East Side aims to examine the discourses and symbolic elements mobilized by actors participating in the "world of crime" to justify or condemn assassinations in poor neighborhoods of the city of Belo Horizonte, Minas Gerais. The research, based on the analysis of police inquiries and interviews, focused on investigating how these actors articulate elements of a moral grammar as a way of justifying the legitimacy of murders or denouncing a death as unjust, which is an offence to be repaired through violent retaliation.

Keywords: homicide, war, morality, retaliation, Belo Horizonte

\section{Introdução}

$\square$ ste artigo ${ }^{1}$ busca examinar os discursos e elementos simbólicos mobilizados por atores inseridos no "mundo do crime" 2 para justificar ou condenar assassinatos na periferia de Belo Horizonte, em Minas Gerais. Dá-se ênfase a como esses atores articulam acusações e narrativas em um esforço de compreender os mecanismos e os conteúdos morais acionados para apontar a "matabilidade" de determinados sujeitos.

A configuração das dinâmicas de homicídios nas periferias de Belo Horizonte frequentemente responde a uma lógica de conflitos violentos - as chamadas "guerras" - entre diversos grupos de jovens armados coexistindo em um mesmo bairro, em uma rede intrincada de alianças, rivalidades e retaliações. Essa pulverização dos integrantes em inúmeros grupos de tamanho reduzido gera um efeito de multiplicação das rivalidades e dos confrontos violentos entre as gangues, o que é apontado como um dos principais fatores para o aumento dos homicídios em Belo Horizonte e nas cidades vizinhas (ROCHA, 2015, 2017; ZILLI, 2004, 2011).

A pesquisa foi realizada na Zona Leste de Belo Horizonte, especificamente nos bairros Alto Vera Cruz, Taquaril e Granja de Freitas, consideradas algumas das localidades mais violentas da capital 
mineira. Foi adotada uma abordagem majoritariamente qualitativa, composta por observação etnográfica por cerca de um ano e meio. Também realizei, no decorrer de 2016, 21 entrevistas em profundidade com atores locais que estiveram no mundo do crime, assim como com lideranças comunitárias e membros de igrejas evangélicas e do movimento hip hop, que têm em comum a atuação junto aos jovens envolvidos com o tráfico de drogas e homicídios nesses bairros. Em paralelo, foram analisados 131 inquéritos policiais de homicídios ocorridos nos três bairros entre 2010 e 2014, como forma de buscar relações, especialmente de caráter retaliatório, entre essas mortes.

\section{A gramática moral do mundo do crime}

Meu interesse inicial nesta pesquisa era verificar quais são os elementos presentes em uma situação de homicídio retaliatório, ou seja, em que contextos um assassinato é cometido como resposta a uma agressão ou ofensa, como forma de controle social, ainda que de caráter privado e violento (BLACK, 1983). No decorrer do trabalho de campo, surgiram diversas narrativas sobre situações de conflitos nas quais os envolvidos tinham interpretações divergentes acerca da matabilidade de um sujeito. A partir daí, elaboravam narrativas e discursos radicalmente divergentes acerca de um mesmo assassinato: um lado pregava a legitimidade da morte de acordo com uma série de elementos morais e simbólicos relacionados ao regime normativo do mundo do crime enquanto o outro elaborava um discurso embasado nesses mesmos elementos morais e apontava o caráter ilegítimo de determinada morte e, não raro, a necessidade de retaliação.

Antes da pesquisa que deu origem a este artigo, pude acompanhar de perto um exemplo dessas possibilidades distintas de articulação de uma gramática moral, durante o período em que trabalhei em uma política pública ${ }^{3}$ voltada para a prevenção dos homicídios em uma favela na região sul de Belo Horizonte. O caso relatado a seguir, que se desenrolou enquanto eu era operador desta política pública, se insere no contexto de uma guerra que existia há anos entre dois grupos do aglomerado Santa Lúcia, mas que havia recrudescido bastante entre 2010 e 2011. Ele ilustra de maneira ímpar a desarticulação dos elementos que compõem a gramática moral do crime e suas distintas formas de operacionalização nas periferias da capital mineira.

Márcio, um dos integrantes centrais da "gangue da Antena", recebeu a visita de seu primo Júlio, morador do bairro Ribeiro de Abreu [na região noroeste de Belo Horizonte], onde tinha uma intensa participação na dinâmica criminal local. Durante a visita de Júlio, o grupo da Antena recebeu a notícia por celular de que alguns de seus rivais da gangue do Beco das Flores estavam bebendo em um bar no limiar do seu território. De posse dessa informação, Júlio combinou com os integrantes do grupo da Antena (do qual 
fazia parte seu primo) de ir armado até o bar, fazer uma compra e, dependendo da situação, executar os rivais, a quem havia visto em algumas fotos mostradas em um celular. ${ }^{4}$ (Registro de campo)

Instrumental neste curso de ação foi o fato de Júlio não ser morador do aglomerado Santa Lúcia e ter passado anos sem frequentá-lo e, portanto, não ser reconhecido pelos rivais de seu primo como uma ameaça em potencial. Assim, Júlio foi até o bar próximo do Beco das Flores, comprou um cigarro, percebeu que o local estava praticamente vazio e que Ronaldo e Juninho, rivais do grupo da Antena, estavam distraídos vendo um jogo de futebol em uma televisão no bar. Júlio então foi ao banheiro, que se situava atrás da dupla, e, ao sair, sacou a arma e disparou diversas vezes contra ambos, matando Juninho e ferindo Ronaldo gravemente. Ao escutar os disparos, Márcio e outros integrantes do grupo da Antena rapidamente se aproximaram do bar em duas motos e deram fuga a Júlio, que na mesma noite retornou ao bairro Ribeiro de Abreu. ${ }^{5}$ (Registro de campo)

Essa situação de um assassinato consumado e uma tentativa de homicídio foi interpretada pelos dois grupos envolvidos de maneiras muito distintas. O grupo da Antena, ao qual Márcio pertencia, alegou entre si durante uma atividade na qual eu estava presente que Júlio tinha disposição e era "sangue no olho", pois não temeu atacar dois rivais do grupo mesmo estando sozinho. Por várias vezes, os jovens integrantes do grupo se referiram a Júlio como alguém que tinha coragem e astúcia e que, por isso, seria sempre bem recebido por eles.

Apenas dois dias após o assassinato de Juninho, em uma visita ao grupo do Beco das Flores, pude conversar com os jovens moradores dali e ouvir sobre a revolta que estavam sentindo com o fato de um amigo ter sido morto e o outro estar internado em consequência do que consideraram uma covardia. A acusação de covardia se baseava no argumento de que os dois jovens do Beco das Flores foram pegos desprevenidos e com a guarda baixa, uma vez que Júlio era, até então, desconhecido e não envolvido diretamente na guerra entre os dois grupos.

Disposição ou covardia, duas interpretações diametralmente opostas sobre uma mesma situação. Elas não destoam quanto aos acontecimentos e o modo como se encadearam, mas divergem sobre a legitimidade da estratégia adotada. Ambos os grupos mobilizaram elementos da gramática moral do crime: as duas partes evocaram a noção de guerra e a matabilidade daqueles que dela participam. Em nenhum momento, o grupo agredido questionou a injustiça da morte em si, mas a forma como o ataque ocorreu. De um lado, foram postos os valores positivos do "sangue no olho" e da "disposição", que seriam comprovados pelo fato de Júlio ter atacado sozinho dois integrantes do grupo rival. Do outro lado, a acusação de covardia, que apontava uma ruptura com o regime moral do crime devido à atuação de uma pessoa até então não envolvida nas dinâmicas de rivalidade em um ataque considerado desleal pelos jovens do Beco das Flores.

Ambas as narrativas, a da disposição e a da covardia, foram veiculadas no interior dos dois grupos, aceitas como legítimas por seus integrantes e atores próximos e organizadas ao redor de elementos da gramática moral do crime. Não houve um clamor generalizado pela intervenção das 
instituições do sistema de Justiça, e a morte de Juninho, um jovem “do crime”, não foi questionada em si mesma pelo grupo ao qual ele pertencia. Na verdade, a revolta estava centrada na forma como o ataque foi orquestrado pelos rivais.

Como duas narrativas diametralmente opostas sobre o mesmo fato podem coexistir e encontrar legitimidade dentro de um mesmo regime normativo? Foi justamente esse tipo de situação, bastante recorrente nos bairros de periferia de Belo Horizonte, que me fez questionar a afirmação, um tanto monolítica, acerca da existência de uma "lei do crime" ou "lei do tráfico" nessas comunidades. Essa noção evoca a existência de uma lei prescritiva que define de antemão o comportamento dos atores e compõe um corpo coerente de regras com o objetivo de regular determinadas atividades da vida social. Como tentei demonstrar, a situação na qual dois grupos rivais se encontram após um assassinato de um de seus integrantes não poderia ser mais distante disso: não somente os elementos que compõem essas narrativas são extremamente difusos e desarticulados, como múltiplas narrativas acerca da verdade são tomadas como legítimas por grupos distintos e por aqueles que agem de acordo com suas orientações.

A partir dessa percepção, incorporo à análise a ideia de uma gramática moral do mundo do crime composta por uma coleção de princípios, práticas, interdições e tipologias que, por si só, não estão prontos, mas devem ser articulados em narrativas morais e operacionalizados pelos atores na forma de acusações ou justificativas. Ao contrário da noção de uma lei do crime que opere como um simulacro do direito estatal e organiza de forma prescritiva as possibilidades de desvio e as penalidades a serem aplicadas aos que os praticam, os elementos da gramática do crime só fazem sentido a partir de uma articulação narrativa de seus tropos, tipologias e demais fragmentos normativos.

A noção de gramática moral do crime se aproxima mais da ideia de um conjunto de elementos considerados potencialmente legítimos na construção de uma narrativa pelos sujeitos do que de uma narrativa já elaborada ou, ainda, de um código ou lei estruturado que é aplicado de maneira constante, com o mesmo peso e com consequências relativamente uniformes. Pareceme que, ainda que o regime normativo do crime seja bastante conciso, com normas e práticas consideradas legítimas, assim como suas interdições e formas de sociabilidade, esses elementos precisam ser operacionalizados pelos atores, ou seja, inseridos em uma narrativa coerente, de modo a operar como justificativa legítima em cada situação específica.

A experiência de campo evidenciou que em cada um desses momentos críticos - quando ocorre uma espécie de ruptura na vida cotidiana, causada pela necessidade de reflexão sobre a situação e a posição que o ator ocupa ou pretende ocupar nela (BOLTANSKI e THÉVENOT, 1999) - , os indivíduos associados às práticas do mundo do crime precisam operacionalizar esse conjunto de normas, interdições, práticas e tipologias que se apresentam de forma difusa, 
conforme o contexto específico daquele momento crítico e de seus envolvidos. A gramática moral do crime e seus elementos são relativamente desarticulados, cabendo aos atores, em meio a suas disputas e conflitos, elaborar uma narrativa que justifique de forma legítima seu curso de ação e até o uso da violência letal. Os elementos abstratos da gramática moral do crime são desarticulados o suficiente para serem operacionalizados de diferentes formas, de acordo com o contexto da situação concreta e os atores nela envolvidos.

\section{Distintas narrativas reivindicatórias por justiça após um assassinato}

Defino o discurso reivindicatório como um argumento que apresenta uma demanda por justiça com posições morais claras sobre quem é o transgressor responsável por determinada ofensa ou agressão e por que ele merece ser punido. Ele compõe o cerne das justificativas de vinganças e retaliações violentas frente a uma agressão ou ofensa real ou imaginária. É também por meio desse tipo de narrativa que o indivíduo que busca ocupar o papel de retaliador vai se proclamar detentor de um direito legítimo de punir aquele que cometeu a ofensa ou a agressão inicial. O discurso reivindicatório é, portanto, um tipo bastante específico de acusação, uma ação na qual um ator se investe do direito de apontar o outro como causa de uma negatividade (MISSE e WERNECK, 2012).

Se a operação básica da acusação é a definição de quem tem a culpa, no discurso reivindicatório essa acusação vem acompanhada de um clamor por sua punição, de forma a restaurar uma noção de justiça ou equidade, que pode ser articulada pelos métodos oficiais do sistema de justiça criminal ou de forma privada e violenta.

A despeito da ênfase desta pesquisa nos homicídios retaliatórios, nem todos os assassinatos geram uma retaliação violenta. Essa é apenas uma das respostas possíveis a um homicídio ou agressão. Uma série de elementos é necessária tanto para que uma morte produza um discurso reivindicatório quanto uma vingança violenta. Assim, parece-me importante voltar o olhar para algumas situações típicas nas quais a retaliação pela força seria improvável e as comparar com aquelas recorrentemente encontradas durante a pesquisa, a fim de tentar compreender as narrativas e justificativas morais dos homicídios retaliatórios à luz de suas especificidades.

Para tanto, apresento seis situações bastante esquemáticas, generalizações que condensam tanto características de alguns dos inquéritos policiais analisados quanto episódios recorrentes encontrados durante meu trabalho em favelas e demais bairros de periferia de Belo Horizonte. Esses seis casos poderiam ser considerados uma espécie de tipos ideais, construtos teóricos artificiais que buscam enfatizar determinados aspectos do fenômeno analisado (WEBER, 2006). Acredito que possam ajudar a pensar sobre as formas 
de articulação de elementos recorrentes da gramática moral do crime, sobretudo as tipologias identitárias presentes nos casos de homicídios retaliatórios: como eles operam e como se diferem dos assassinatos que não provocam retaliações.

- Situação 1: Em um bairro de periferia de Belo Horizonte, com elevado número de crimes violentos, uma pessoa tida como "vacilão"6 ou "noiado"7 é morta, e a identidade de seu(s) algoz(es) é publicamente conhecida. Ainda que a vítima tenha familiares e amigos no bairro, é improvável que seu assassinato seja vingado e gere grande comoção, tanto na mídia quanto na própria comunidade.

- Situação 2: Nesse mesmo bairro de periferia, um jovem considerado do crime é morto por rivais, também identificados com a criminalidade violenta. Via de regra não haverá grande mobilização comunitária em torno desse assassinato, mas é concreta a possibilidade de que sua morte seja vingada por familiares ou amigos.

- Situação 3: Ainda na periferia de Belo Horizonte, uma pessoa conhecida por cometer roubos dentro do próprio bairro ou crimes sexuais é morta por um grupo de comerciantes ou linchada por pessoas que não são necessariamente identificadas com o mundo do crime. A possibilidade de retaliação diante dessa morte é remota, ainda que ela possa gerar alguma repercussão na mídia.

- Situação 4: Mais uma vez em um bairro periférico tido como violento, o assassinato de um jovem conhecido como "trabalhador" 8 ou de uma liderança comunitária local tem grande chance de gerar comoção nos moradores, em outras lideranças comunitárias e provavelmente na mídia. Há a possibilidade de uma vingança por pessoas que podem considerar a morte injusta.

- Situação 5: Em um bairro de periferia, duas pessoas não consideradas do mundo do crime se desentendem. Ocorre um homicídio, decorrente de uma briga de vizinhos ou crime de caráter passional. Há a possibilidade de que essa morte seja vingada, a depender da rede de relações da vítima e de como ela percebe o assassinato.

- Situação 6: Durante um assalto em um bairro de classe média de Belo Horizonte, o assaltante mata sua vítima. Um crime com essas características provavelmente terá vasta repercussão na mídia mineira. São maiores as chances de o assassino ser preso pela polícia do que de ser morto por parentes e amigos da vítima.

Esses seis esboços de situações de homicídios e suas eventuais repercussões obviamente não contemplam todas as dinâmicas complexas dos homicídios em Belo Horizonte, tampouco as relações entre os atores e as consequências. No entanto, ajudam-nos a pensar sobre alguns dos elementos que podem levar a vinganças de uma morte e, principalmente, a compreender arranjos possíveis de narrativas morais e gramáticas normativas sobre esses assassinatos. 
O primeiro desses elementos é a região da cidade na qual se deu a morte inicial. As vinganças não são uma exclusividade de bairros de periferia com um histórico de criminalidade violenta, mas, aparentemente, tendem a se concentrar neles - embora essa seja uma afirmação que careça de estudos empíricos no contexto brasileiro. Ainda assim, parece-me uma hipótese coerente supor que, tal como os homicídios, as vinganças relativas a mortes violentas também aparentam se distribuir de maneira desigual pelos bairros de Belo Horizonte (DINIZ e LACERDA, 2010; BATELLA e DINIZ, 2010). Então, além de se associar diretamente ao perfil socioeconômico da vítima e, sendo assim, aos maiores ou menores esforços das instituições do sistema de justiça criminal na solução em tempo hábil do crime, o local do assassinato - cabe pressupor - também pode determinar a possibilidade de adoção de um discurso reivindicatório por meio violência privada.

Como este estudo se concentrou em homicídios cometidos nos três bairros de periferia da Zona Leste de Belo Horizonte, a distinção entre o status socioeconômico dos bairros e das vítimas e sua associação ou não aos homicídios retaliatórios não será aqui abordada profundamente e será assunto de pesquisas futuras. O importante por ora é ressaltar que, assim como os demais serviços do Estado, as instituições do sistema de justiça criminal não operam de forma homogênea em todos os bairros de Belo Horizonte. As formas de atendimento diferenciadas nas margens do Estado dizem mais sobre as escolhas políticas a respeito desses territórios e de suas populações, da lógica de distribuição de recursos econômicos e políticos do que de sua escassez proclamada pela tese sobre a ausência do Estado (DAS e POOLE, 2004).

Um elemento mais central ao conteúdo moral acerca do homicídio e das demandas por justiça dele decorrentes é a identidade pública dos atores envolvidos, especialmente a da vítima. Ela terá um papel importante na determinação das narrativas morais associadas à sua morte e nos públicos mobilizados por elas. As tipologias que compõem o repositório da gramática moral do mundo do crime e aparecem nessas situações, como "trabalhador", "noiado", "vacilão" e "bandido", são categorias que utilizo aqui não para definir as práticas desses indivíduos, mas para identificar a forma como são percebidos por grande parte da comunidade na qual se inserem. Nesse sentido, interessa menos saber se a vítima realmente era, por exemplo, noiada, mas quais os efeitos da circulação de uma tal narrativa tida como legítima.

\section{'Aquele que deve ser morto'}

A morte de pessoas enquadradas em certas categorias específicas da gramática moral do crime quase nunca é digna de vingança. Pelo contrário, não raro a noção de justiça está associada à eliminação desses indivíduos, como, por exemplo, quando se trata de pessoas acusadas de 
roubar dentro do próprio bairro, de cometer crimes sexuais ou de fazer delações para a polícia. Assim, categorias como "noiado", "X9" e "vacilão" são utilizadas em narrativas elaboradas para rotular pessoas que se relacionam com as práticas criminosas e estão inseridas de alguma maneira no mundo do crime. Elas são vistas como não aderentes a alguns dos valores mais centrais de seu regime normativo, sendo, portanto, tidas como "erradas no crime".

Nos casos de indivíduos assim identificados, o significante da justiça muitas vezes não se vincula a uma eventual vingança por suas mortes, mas à própria execução desses atores, vistos como figuras que romperam tanto com os códigos normativos convencionais quanto com aqueles que compõem uma gramática moral do crime. Por isso, suas execuções têm repercussão comunitária reduzida e pouco interesse em uma mobilização retaliatória.

Rogério, 27 anos, morador do Alto Vera Cruz, era usuário de crack e havia perdido o emprego no ano anterior. Segundo sua mãe e a sua ex-esposa, desempregado, Rogério passou cada vez mais tempo na boca do Cruzeirinho, onde também fazia pequenos trabalhos e atuava como olheiro, avisando a chegada da polícia em troca de drogas. Essa situação levou Fernanda, então sua esposa, a pedir o divórcio, e Rogério voltou a morar com sua mãe.

Cerca de dois meses antes de sua morte, Rogério foi espancado e expulso da boca do Cruzeirinho, segundo sua mãe, por não ter vigiado corretamente e alertado da chegada de policiais, que prenderam algumas pessoas na boca e drogas. Após se recuperar, Rogério passou a tentar se firmar como olheiro em outros pontos de vendas de drogas para manter o uso frequente, mas sem muito sucesso, de forma que sua mãe sustentava seu vício enquanto insistia para que ele procurasse um tratamento.

Antes de sua morte, Rogério saía cada vez menos de casa e havia dito à sua mãe que "não precisava mais olhar tratamentos para ele, já que não passaria daquela semana", sem, no entanto, Ihe dizer o motivo daquela afirmação. Três dias depois ele foi morto por cinco tiros quando saía de casa. A Polícia Civil não identificou autores ou suspeitos do crime. (Inquérito 144/2014. Acervo pessoal)

O assassinato de Rogério é apenas um entre os muitos casos semelhantes encontrados na pesquisa: situações em que as vítimas foram consideradas pessoas sem uma conduta adequada na esfera moral do mundo do crime, cujas mortes foram aparentemente decididas e executadas por um grupo e não geraram retaliação - ao menos, não uma retaliação violenta registrada no sistema de justiça criminal.

O assassinato de Rogério, cuja trajetória parece ter sido bastante próxima da tipologia do noiado e, portanto, profundamente relacionada ao tráfico e uso de drogas, pode ser lido como uma retaliação por um erro: o de não ter cumprido de maneira satisfatória seu papel de olheiro ocasionando algumas prisões. Por esse erro, foi espancado e expulso da boca. Mas, devido ao vício, continuou circulando pelas bocas da região.

Nos depoimentos de Rosana, sua mãe, e Fernanda, sua ex-esposa, Rogério é descrito como alguém sem muitos recursos financeiros, discursivos ou mesmo violentos para definir outro tipo de 
relação com aqueles que regiam os pontos de vendas de drogas próximos à sua casa. Era visto como um usuário desesperado, alguém não respeitado por outros atores do mundo do crime por supostamente se sujeitar ao risco de ser agredido física e simbolicamente em troca de uma dose de droga ${ }^{9}$. A acertada - e, por essa razão, impactante - afirmação para a mãe de que não viveria até a semana seguinte demonstra tanto uma profunda clareza sobre sua situação quanto a total falta de recursos para alterá-la. Não há como saber se, nesse intervalo, ele tentou buscar intermediários, negociar com patrões das bocas locais ou se o que agravou ainda mais sua situação foram dívidas ou outros desentendimentos adicionais. $\mathrm{O}$ fato é que, como ele havia previsto, sua vida teve fim.

"Noia", "X9", "rato de boca", "estuprador" ou "agressor de mulheres” são tipos negativos centrais à gramática moral do crime. Quando empregados de maneira bem-sucedida, podem vir a solapar por completo outras características dos atores. Essas categorias identitárias são tipos, elementos de uma gramática moral específica que portam legitimidade a determinada população e àqueles em contato com seus atores e práticas. São tipos de indivíduos, não de ações, embora sua característica central seja a associação com determinada ação, vista como inaceitável no regime moral do mundo do crime. Em última medida, têm como ponto comum o fato de representarem pessoas que "atrasam" os outros, ou seja, geram problemas, conflitos e desconfiança, e que se relacionam com o mundo do crime, mas não têm legitimidade. Como diz o funk de MC Orelha (2011), "na vida errada você tem que andar certo"10. Esses tipos representam aqueles que "andam errado na vida errada" e são, portanto, atores que devem ser eliminados.

\section{'Aquele que pode ser morto'}

Outras possibilidades de narrativas morais podem ser articuladas em situações que envolvem o assassinato de alguém publicamente identificado como do jeito certo do crime. Ainda que causem comoção entre familiares e vizinhos, essas mortes tendem a ser vistas por parte da comunidade como um destino esperado para o indivíduo que enveredou pela carreira criminosa, gerando repercussão local, mas pouca ou nenhuma mobilização política das lideranças e associações comunitárias.

Se por um lado o assassinato de um jovem reconhecido publicamente como do crime, ou simplesmente tido como bandido ou ladrão, costuma não causar comoção fora de seu círculo mais próximo de amigos e familiares, por outro, sua morte pode vir a mobilizar seus pares, que compartilham de valores favoráveis à resolução violenta, a correr atrás. Ou seja, podem devolver a agressão na mesma moeda, tentando matar aquele que cometeu o assassinato ou alguém 
próximo a ele, resultando em cadeias de homicídios retaliatórios que podem durar por longos períodos - as chamadas guerras.

A morte de atores pertencentes ao mundo do crime, quando fazem partes de grupos armados ou gangues da região, pode resultar em longas guerras e em cadeias de homicídios retaliatórios nos quais ambos os lados do conflito se atacam. Tais dinâmicas tendem a se fortalecer, uma vez que incentivam a entrada de novos participantes para vingar a morte de parentes e amigos.

Eugênio, 27 anos, morador do Taquaril, foi indiciado por um homicídio cometido em 2009, que teve como vítima Pedro Paulo. Pedro Paulo, por sua vez, tinha 22 anos, também era morador do bairro e possuía uma série de registros no sistema de justiça criminal por assalto e tráfico de drogas. De acordo com as investigações sobre esse crime, a motivação fora um suposto relacionamento extraconjugal mantido entre lara, esposa de Eugênio, e Pedro Paulo. Após o homicídio, lara se mudou do bairro e Eugênio passou a ser ameaçado sistematicamente por alguns dos amigos e familiares de Pedro Paulo.

Oito meses depois, já em 2010, Eugênio estava em um bar na frente de sua casa, do qual Ramon era proprietário. Ao ver que um primo de Pedro Paulo havia passado de moto duas vezes na frente do estabelecimento, Ramon teria pedido a Eugênio para ir embora, pois esse sabia que "não podia ficar no meio do pessoal" por estar ameaçado. Eugênio tomou mais uma cerveja e quando estava pagando a conta, foi atingido por três disparos feitos por dois homens em uma motocicleta, sendo que Ramon identificou um deles como "Neguinho", primo de Pedro Paulo. (Inquérito 006/2010. Acervo pessoal)

Em agosto de 2012, Marcos "Canela", morador do Granja de Freitas de 19 anos de idade, foi morto a tiros, segundo diversas testemunhas, assassinado por Fernando e Juan, de 18 e 19 anos respectivamente, também moradores do bairro. Segundo as investigações, esse homicídio foi motivado por um desentendimento entre o trio, até então parceiros, devido ao sumiço de uma pistola que teria sido guardada por "Canela".

Após a morte de Marcos "Canela", seu irmão mais novo, Fabiano, de 16 anos, comentou com várias pessoas do bairro que mataria os algozes de Marcos e, por isso, adquiriu uma arma de fogo, se envolvendo posteriormente em trocas de tiros com Fernando e Juan. Em um desses episódios, Fabiano foi ferido na perna e, segundo sua mãe, após muita insistência, aceitou se afastar do bairro, indo morar por três meses na casa de uma tia no município de Ribeirão das Neves.

Nesse interim, Fabiano e seus rivais Fernando e Juan trocaram mensagens de celular, nas quais lentamente construíram uma espécie de trégua e deram por encerrada a guerra entre o trio. Alguns dias após esse combinado, Fabiano retornou para a casa de sua mãe no Granja de Freitas.

No dia de sua morte em novembro de 2012, Fabiano estava em casa quando ouviu seu nome ser chamado na rua por uma voz feminina. Ao abrir a porta, foi baleado duas vezes por Juan, que segundo a mãe de Fabiano, estava acompanhado de Fernando e uma adolescente não identificada. (Inquérito 060/2012. Acervo pessoal)

A morte de Eugênio aparenta ser um caso clássico de retaliação: ao matar Pedro Paulo, Eugênio se colocou como uma vítima em potencial, alguém que provavelmente seria atacado por amigos e familiares daquele que foi morto. A sua identidade pública como alvo de uma retaliação violenta era tão difundida que Ramon, o dono do bar, pede que Eugênio vá embora, frente ao risco de esse ser alvo de um ataque armado dentro do estabelecimento. 
Já o assassinato de Fabiano parece seguir um modelo mais complexo no qual, após buscar vingança pela morte do irmão, Fabiano é ferido e articula uma trégua com seus rivais, apenas para ser pego desprevenido e assassinado enquanto desarmado na porta de casa. De acordo com o depoimento de Maria, mãe de Marcos e Fabiano, enquanto o irmão mais velho tinha envolvimento com o tráfico de drogas, tanto no bairro onde moravam antes quanto no Granja de Freitas, para onde a família se mudou em 2008, Fabiano não tinha envolvimento com práticas criminosas, estudava de dia e trabalhava como ajudante de cozinha em um restaurante no período noturno. Maria conta que, após o assassinato de Marcos, Fabiano saiu do emprego e passava as noites fora de casa, às vezes escondido buscando formas de pegar de surpresa os algozes de seu irmão mais velho. Ainda segundo a mãe dos jovens assassinados, ela iria se mudar o mais rápido o possível de volta para o município de Ribeirão das Neves, onde morara anteriormente. Apesar de Fernando e Juan terem sido presos, ela temia que Michel, de 14 anos e seu único filho ainda vivo, também enveredasse na busca por vingança pela covardia cometida contra Fabiano.

$\mathrm{O}$ assassinato do bandido, considerado um ator legítimo do mundo do crime, em contraste com a categoria descrita previamente, ou seja, de atores vistos como desviantes do crime, pode trazer um significado duplamente simbólico e, à primeira vista, paradoxal. A morte de alguém inserido de forma legítima no mundo do crime representa, em primeiro lugar, um destino já prenunciado em alguma medida e, nesse sentido, tais mortes tendem a não causar grande comoção nos bairros em que acontecem por serem de alguma forma esperadas. Por outro lado, há a possibilidade de que esses homicídios sejam objetos de discursos reivindicatórios que demandem uma retaliação violenta, por meio do qual os elementos da gramática do crime serão articulados para demandar uma agressão contra o algoz ou, eventualmente, contra pessoas próximas a ele.

O relato do assassinato de Fabiano, um adolescente que não estava inserido na dinâmica criminal local, mas decidiu se vingar violentamente dos algozes de seu irmão, é importante para demonstrar que esse discurso reivindicatório composto por elementos da gramática do crime não é mobilizado somente por atores diretamente inseridos nas dinâmicas criminais desses bairros. Conforme observa Feltran (2011, p. 315) em suas pesquisas nas periferias de São Paulo, é possível presenciar uma "maior amplitude de circulação, interna às periferias, de um marco discursivo do crime, que passa a disputar espaço de legitimação nas sociedades locais, especialmente entre os jovens, embora não seja nem dominante nem hegemônico ali”. Um discurso reivindicatório que aponta para a necessidade de uma vingança violenta pode ser elaborado, portanto, também por atores que não estão inseridos diretamente no mundo do crime, mas que compartilham dos elementos dessa gramática, desse marco discursivo para elaborar uma narrativa moral que valide uma retaliação violenta. 
O jovem do crime é alguém que pode ser morto a qualquer instante, mas cuja morte tem uma grande chance de ser vingada por meio de uma nova agressão ou assassinato. Ao contrário das categorias identitárias negativas presentes na gramática do crime, como o "noiado", "X9", "rato de boca" e "estuprador", cujo extermínio não gera repercussões no sentido de narrativas morais sobre revides e reestabelecimento de uma justiça local, o ator tido como correto no mundo do crime é passível de ser morto, mas sua morte tem grande chance de gerar um discurso reivindicatório que aponta para a necessidade de uma vingança violenta.

\section{'Aquele que não pode ser morto'}

Finalmente, as percepções acerca das vítimas de um homicídio podem se inserir em tipos idealizados, aqueles totalmente externos ao mundo do crime. Categorias como "trabalhador", "estudante" e "liderança" comunitária são alguns dos tipos que se referem a atores não envolvidos no crime e, por isso, idealmente não deveriam ser prejudicados. $\mathrm{O}$ assassinato de alguém não identificado com a criminalidade, que não se esperava ser morto, pode vir a evocar uma maior repercussão política por meio da mobilização comunitária.

As situações que envolvem balas perdidas, ou seja, pessoas atingidas no fogo cruzado que não estavam participando dele. Parecem-me casos típicos desse tipo de situação de homicídio: um inocente é morto ou ferido em uma disputa entre atores que, em alguma medida, pertencem ao mundo do crime. Dentre os casos analisados, em alguns episódios - ainda que mais raros que os tipos apresentados anteriormente - transeuntes foram atingidos por disparos; em alguns deles, os próprios agressores procuraram as vítimas para pedir desculpas e justificar a circunstância que causou o ferimento.

Carlos, de 34 anos, morador do bairro São Geraldo, havia saído da cadeia recentemente, após cumprir pena por assalto à mão armada. Segundo sua esposa, Simone, Carlos mantinha uma rotina de horários erráticos, às vezes voltando com muito dinheiro. Ao ser questionado certa vez, disse que o dinheiro era proveniente de "saidinhas de banco" que cometia em bairros de classe média.

No dia de seu assassinato, Carlos estava pilotando sua moto no bairro Taquaril com o jovem Max, de 16 anos, na garupa. A dupla avistou outro motoqueiro em sentido contrário e parou no meio da rua para conversar. Subitamente Max sacou uma arma e matou Carlos com vários tiros, fugindo com o outro motoqueiro. No entanto, um dos disparos também atingiu as costas do adolescente Alex, de 13 anos, que, no momento do homicídio, voltava da escola.

Dias após o ocorrido, logo que Alex teve alta do hospital, Max foi à casa da família e se desculpou com o jovem e sua mãe. Ele também se comprometeu a arcar com os gastos com remédios e justificou o ocorrido dizendo que Carlos tinha um relacionamento com sua irmã Júlia, de 19 anos, e que a havia agredido quando ela quis terminar o namoro. (Inquérito 016/2010. Acervo pessoal) 
Atores não envolvidos com as práticas do mundo do crime não estão fora do alcance das narrativas dessa esfera moral. Mesmo de fora do crime, tornam-se objetos de seu marco discursivo. Porém, como tenho argumentado, são a operacionalização e a articulação dos elementos de uma gramática moral do crime que vão garantir a legitimidade ou não de uma ação frente a outros atores inseridos no mundo do crime. Assim, noções como "trabalhador" ou "liderança" comunitária são em si mesmas categorias, tipos, classificações que podem ser ajustadas e organizadas de maneira a ter prioridade ou não em relação a outros elementos da referida gramática.

Uma situação relativamente antiga, ocorrida na década passada no Taquaril, parece ilustrar bem a operação que tento descrever. Em 2003, Marli, uma liderança comunitária bastante conhecida no bairro, onde atuava desde sua ocupação, na década de 1980, participava, em companhia de sua filha Simone, das reuniões do Conselho Comunitário de Segurança Pública (Consep). Lideranças comunitárias locais e policiais militares responsáveis pelo policiamento no bairro discutiam estratégias para prevenir a criminalidade na região. Em certo momento, mãe e filha foram alertadas por vizinhos que pessoas envolvidas com o tráfico de drogas no bairro estavam perguntando a respeito do conteúdo desses encontros com a polícia e que as duas estavam sendo chamadas de X9 por um determinado grupo. Em uma noite de sábado, as duas mulheres foram retiradas de casa à força por homens armados e executadas a tiros em um beco próximo.

O caso gerou bastante repercussão na imprensa à época. Segundo alguns entrevistados, provocou revolta, inclusive entre os atores do mundo do crime, que consideraram o duplo homicídio uma covardia. Entretanto, não houve retaliação, pois os responsáveis foram presos pouco depois em um município vizinho, onde estavam escondidos.

$\mathrm{O}$ caso evidencia que os tipos e classificações positivas, mesmo aqueles que se referem a atores e ações externos às práticas criminais locais, são passíveis de alteração frente à organização de narrativas morais a partir dos elementos da gramática moral do crime. Marli teve sua atuação nos espaços coordenados pela Polícia Militar interpretada, pelo menos por um dos grupos armados do bairro, como uma espécie de delação. Eles elaboram uma narrativa na qual o trabalho histórico como liderança comunitária de Marli é solapado por sua suposta colaboração com a polícia, o que operaria uma transformação de seu papel de liderança para X9.

Nessa argumentação, Marli e Simone saem do lugar de pessoas que não podem ser mortas para o de pessoas matáveis, que prejudicariam os integrantes do grupo. No entanto, após o duplo homicídio, outros atores inseridos na dinâmica criminal local questionaram a justificativa dos autores das execuções, apontando para a covardia de assassinar as duas mulheres. Assim, houve uma ruptura entre os grupos, que compartilham do mesmo léxico discursivo do mundo do crime mas divergem sobre o enquadramento moral de determinada situação o que pode levar a novos conflitos e violências. 
O assassinato de alguém que não pode ser morto abre duas possibilidades de demanda por justiça. Esses crimes em geral causam uma maior mobilização da população do bairro como um todo e, eventualmente, da mídia e de instituições do sistema de justiça criminal. Afinal, a vítima é enquadrada sob a perspectiva ampliada do inocente, alguém que não contribuiu para com sua própria morte. Nesses casos, como foi observado no caso do assassinato de Marli e Simone, a ação das polícias tende a ser bastante rápida, e o sistema formal de justiça acolhe a reivindicação por reparação. No entanto, existe sempre a possibilidade de que a revolta e a indignação causadas por essas mortes sejam transformadas em um discurso reivindicatório a favor de uma retaliação violenta por parte de atores que compartilham da gramática moral do mundo do crime e que tinham alguma relação ou estima pela vítima.

\section{Um quadro analítico das demandas por justiça após um homicídio}

A discussão acerca dos elementos mais difundidos da gramática moral do crime e de como eles compõem tipos e classificações de sujeitos se estrutura neste trabalho de forma a nos permitir pensar sua apropriação por narrativas sobre ações do mundo do crime e sua legitimidade. Esses elementos fazem parte de um repositório mais amplo de normas, tipos e significados que integram o regime normativo do crime, articulados de acordo com cada contexto, atores envolvidos e suas habilidades de operacionalização dessa gramática. Interessa-me, portanto, a forma como esses elementos são arranjados, de modo a compor estruturas mais ou menos sólidas de tipologias de homicídios e as demandas por justiça que desencadeiam.

As seis situações esquemáticas de homicídios aqui expostas são algumas dessas formas recorrentes de articulação dos elementos da gramática do crime no contexto de Belo Horizonte. A partir desses casos ideais e das categorias neles ressaltadas, elaborei um quadro analítico da interação entre contexto, narrativas e possível repercussão e retaliação violenta (Tabela 1).

A primeira coluna lista os casos típicos. As duas colunas seguintes são dedicadas à percepção sobre pertencimento da vítima e do agressor, respectivamente, ao mundo do crime. As demais colunas indicam se o caso típico ocorreu em um bairro de periferia violento, seu potencial de repercutir em organismos de representação política e na mídia e se existe uma grande chance de que esse homicídio seja seguido de uma retaliação violenta.

Tabela 1: Elementos de um homicídio e sua relação com a possibilidade de vingança 


\begin{tabular}{|c|c|c|c|c|c|}
\hline \multirow[t]{2}{*}{ Caso típico } & \multicolumn{2}{|c|}{$\begin{array}{l}\text { Envolvimento } \\
\text { com mundo do } \\
\text { crime }\end{array}$} & \multirow{2}{*}{$\begin{array}{l}\text { Bairro de } \\
\text { periferia } \\
\text { violento }\end{array}$} & \multirow[t]{2}{*}{$\begin{array}{l}\text { Repercussão } \\
\text { externa }\end{array}$} & \multirow[t]{2}{*}{ Vingança } \\
\hline & Vítima & Agressor & & & \\
\hline $\begin{array}{l}\text { Assassinato de alguém } \\
\text { considerado noiado ou vacilão }\end{array}$ & + & + & + & - & - \\
\hline $\begin{array}{l}\text { Assassinato entre atores certos no } \\
\text { crime }\end{array}$ & + & + & + & - & + \\
\hline $\begin{array}{l}\text { Linchamento ou extermínio de } \\
\text { alguém acusado de roubar no } \\
\text { bairro ou cometer estupros }\end{array}$ & + & - & + & + & - \\
\hline $\begin{array}{l}\text { Crime passional, } \\
\text { desentendimentos etc. }\end{array}$ & - & - & + & - & $+/-$ \\
\hline $\begin{array}{l}\text { Assassinato de uma pessoa } \\
\text { considerada trabalhadora }\end{array}$ & - & + & + & + & $+/-$ \\
\hline $\begin{array}{l}\text { Morte durante um assalto em } \\
\text { um bairro de classe média }\end{array}$ & - & + & - & + & - \\
\hline
\end{tabular}

Fonte: Elaboração própria.

O quadro não tem como objetivo compor um catálogo completo ou exaustivo das situações de homicídio possíveis na capital mineira. Meu propósito foi isolar alguns casos típicos ou idealizações de casos a fim de compará-los no que diz respeito à elaboração de narrativas. Embora repleto de lacunas e com um alto grau de simplificação de uma realidade complexa e repleta de discursos divergentes, pode ser útil como ferramenta de investigação ao realçar padrões e consistências.

No assassinato de Rogério, a naturalização da morte de alguém visto como um noia ou noiado, alguém errado no crime, que deixa falhas, é incorporada pelo próprio Rogério. $\mathrm{O}$ inquérito policial sobre o assassinato não tinha sequer suspeitos identificados dois anos depois do ocorrido, embora testemunhas tenham apontado a boca onde ele havia sido ameaçado e os apelidos de alguns de seus integrantes e potenciais suspeitos.

Por outro lado, no caso do assassinato de Marli e sua filha, aparentemente houve uma discordância sobre sua matabilidade e o enquadramento moral das vítimas. O duplo assassinato não encontrou legitimidade entre outros atores e grupos inseridos no mundo do crime, que, inclusive, de acordo com alguns dos meus interlocutores, sinalizaram a intenção de punir os algozes das duas, mas eles foram presos pouco tempo depois. É importante ressaltar que o caso teve repercussão na mídia mineira e que os policiais foram pressionados a solucioná-lo.

Até aqui, detive-me em alguns dos tipos e classificações dos atores de acordo com a gramática moral do crime, pois parece-me que a identidade pública dos envolvidos, especialmente das vítimas, é um ponto fundamental na articulação ou não de um discurso local que demanda justiça sobre sua morte e se essa reivindicação aponta para o sistema de justiça convencional ou para uma reparação de forma privada e violenta. 
A morte de um jovem reconhecido como trabalhador vai gerar um tipo de repercussão e mobilização, enquanto a morte de outro envolvido com o mundo do crime terá uma repercussão muito mais contida, podendo até ser considerada legítima por determinados atores. Coloca-se, então, uma questão central: por que a morte de alguém identificado como trabalhador ou liderança, que tende a causar mais comoção naquela vizinhança e também possível mobilização visando a uma maior repercussão externa, não traz necessariamente a certeza de uma vingança violenta, ao passo que a morte de um bandido, alguém do mundo do crime, cujo fim em alguma medida é antecipado, que causa uma repercussão muito mais contida, tem grandes chances de motivar outra agressão ou homicídio?

Tenho desmembrado a vingança violenta em duas partes: a elaboração de um discurso reivindicatório e a agressão propriamente dita. Nos casos de assassinato em que é elaborada uma narrativa legítima ${ }^{11}$ para o crime, por exemplo descrevendo a vítima como X9, noiado, dificilmente haverá discurso reivindicatório. A vítima é considerada duplamente desviante: tanto em relação às leis e às normas convencionais, quanto no que se refere aos códigos normativos comuns ao mundo do crime. Durante a análise dos inquéritos policiais, não foram raras as vezes em que os próprios familiares das vítimas, ao testemunharem sobre as circunstâncias de suas execuções, apontaram que, apesar dos alertas e agressões sofridas previamente, a vítima continuou mantendo um curso de ação considerado perigoso na comunidade, o que, de alguma forma justificaria seu assassinato.

A esfera moral do crime, seus valores e práticas que compõem o elemento do proceder, a noção de uma conduta ética no mundo do crime ${ }^{12}$. Assim, nos tipos imaginados em que se articula uma narrativa de inclusão da vítima no mundo do crime de forma positiva, a chance de vingança é elevada. Nesses casos, não só são grandes as possibilidades de a vítima integrar uma rede social e moral de pessoas que compartilham elementos da gramática moral do crime e que apontam para a resolução privada e violenta, como também é provável que elas possam elaborar uma narrativa moral sobre a necessidade de retaliação, por meio de um discurso reivindicatório que acusa os algozes e demanda por vingança violenta.

Já a morte violenta daqueles identificados de maneira negativa no crime não mobilizará uma vingança. Isso se dá pois, ainda que as vítimas possivelmente integrem uma rede social e moral que compartilha de valores, práticas e sociabilidades do crime, reconhecem que a vítima se colocou em uma situação em que se tornou alguém matável.

Nos tipos de homicídios nos quais a narrativa elaborada ressalta seu não envolvimento com o mundo do crime, não existe o pressuposto da matabilidade. Isso pode fomentar uma mobilização comunitária, uma maior repercussão sobre o crime e um discurso que demanda por justiça, o qual, como via de regra, terá como interlocutores a mídia e a esfera pública de forma mais ampla. Nesses casos, é provável que seja mobilizado um discurso que reivindica a justiça e busca sua responsabilização, pressionando o sistema de justiça e seus operadores para que o autor seja preso e 
condenado ou, ainda, que tome medidas para evitar que aquela situação se repita. Também fica aberta a possibilidade da existência de uma rede de atores próximos da vítima que compartilhem de elementos morais do mundo do crime, de forma a elaborar um discurso reivindicatório que aponte para uma vingança violenta. Por isso a possibilidade de vingança para essas situações é marcada como simultaneamente positiva e negativa (Tabela 1): embora a ofensa seja percebida de forma hegemônica (a morte de alguém que não era do crime), o discurso que demanda por sua reparação pode se voltar tanto para o Estado quanto para a resolução privada e violenta.

Finalmente, o caso do homicídio cometido em um bairro de classe média de Belo Horizonte destoa quanto à possibilidade de vingança. $\mathrm{O}$ caso representa as diferentes atuações das instituições de segurança pública em periferias e favelas de acordo com estratégias de atuação do Estado, especificamente no que tange à segurança pública e ao controle das populações em suas margens.

\section{Considerações finais}

A noção de gramática moral do crime é composta por elementos de diversas origens que têm em comum o fato de serem utilizados recorrentemente para a atribuição de significado a certos valores, práticas, tipos e condutas associados ao mundo do crime. Os elementos específicos dessa gramática variam de acordo com o bairro, a cidade e as práticas criminais, assim como as possibilidades de articulação das narrativas morais que os incorporam e seus limites de acordo com a estruturação das atividades criminosas locais. Busquei neste artigo não apenas apresentar a noção de gramática moral do mundo do crime, mas também explorar como seus elementos são articulados na construção de discursos reivindicatórios por justiça após um assassinato, sobretudo em disputas envolvendo atores inseridos na dinâmica criminal dos bairros de periferia em Belo Horizonte.

Optei por não mergulhar em uma tentativa de catalogação de um sem número de elementos dessa gramática, mas dedicar esforços à exploração das distintas formas como eles são operacionalizados em narrativas morais recorrentes sobre as práticas do crime. Ainda que essa opção tenha resultado em um argumento menos sistemático e coeso do ponto de vista analítico, espero ter evidenciado o caráter fragmentado, situacional e, muitas vezes, contraditório das formas como os elementos da gramática moral do crime são articulados em Belo Horizonte.

Tentei discutir esse léxico ou marco discursivo do crime por meio de tipologias de situações e suas justificativas, em articulações recorrentes e bastante difundidas a respeito de elementos da gramática do crime. Mas de maneira alguma elas compreendem a totalidade de narrativas morais acerca do crime ou, ainda, impedem que essas narrativas recorrentes não possam ser alteradas e articuladas de formas distintas, dependendo tanto das características específicas da situação 
quanto do poder e da capacidade dos envolvidos de operacionalização da gramática moral do crime em um discurso que seja considerado como legítimo.

Como busquei demonstrar, nem todo homicídio mobiliza uma demanda por justiça, assim como nem todo discurso reivindicatório que aponta a injustiça de determinada morte leva necessariamente a uma retaliação violenta.

Chamar a atenção para o assassinato como um ato que precisa ser reparado é o primeiro passo tanto para a cobrança de uma ação eficaz do Estado no provimento de justiça quanto para a decisão por uma resolução privada e violenta. Em alguma medida, essa escolha estará embutida na forma como o discurso de reivindicação por justiça é elaborado e direcionado.

Em busca de uma resolução pública, mobiliza-se a mídia, as manifestações coletivas (passeatas, fechamento de vias e campanhas), organizações não governamentais e canais de acesso a representantes eleitos. Isso se dá por meio de um discurso que frequentemente parte do individual para o geral, de uma morte violenta específica para uma noção mais ampla, seja essa acerca da violência urbana e das medidas necessárias para combatê-la, como o aumento da presença policial nas ruas ou uma maior punição aos criminosos. Pode se dar ainda com manifestações que busquem maior controle das polícias e de sua violência, especialmente quando operam em favelas e bairros de periferia.

Já o discurso reivindicatório mobilizado para uma forma de justiça privada, violenta e ilegal evidentemente não terá os mesmos interlocutores, mas atores que também identificam a morte inicial como uma injustiça que precisa ser corrigida. Eles compartilham a noção de que essa reparação deve ser feita por meio de outro homicídio ou agressão, em uma composição do que tenho chamado até aqui de rede social e moral de atores próximos à vítima. $\mathrm{O}$ discurso reivindicatório que se segue ao assassinato de uma pessoa considerada como do crime será voltado para, além de parentes e amigos próximos, aqueles que compartilham parte dos códigos, sociabilidades e práticas recorrentes no mundo do crime e operacionalizam a justificativa para a vingança por meio da articulação de elementos de sua gramática moral. Como demonstra Zilli (2011), nas periferias da Região Metropolitana de Belo Horizonte, a dinâmica da retaliação se alastra por meio dessa rede social e moral da vítima e dos demais envolvidos, inserindo novos atores nesses conflitos violentos e reafirmando um léxico discursivo e de práticas consideradas legítimas nesse regime normativo.

A demanda por justiça é endereçada a públicos distintos, de acordo com as narrativas produzidas sobre o homicídio e os atores nele envolvidos. Uma parcela reduzida dessas mortes vai se tornar pauta de ações comunitárias, visando pressionar a atuação das polícias e dos demais órgãos do sistema de justiça. A maioria dessas mortes não produzirá repercussão significativa fora dos bairros onde ocorreram, o que torna ainda mais reduzidas suas chances de serem apuradas de maneira rápida e precisa ${ }^{13}$. Destacam-se os casos de homicídio entre atores percebidos como do crime, assassinatos que geram baixos níveis de comoção e mobilização e cujo discurso 
reivindicatório tem como função não apenas apontar a injustiça cometida, mas ressaltar a necessidade de retaliação violenta - o segundo momento de um processo de vingança.

Para que isso ocorra, no entanto, é necessário que uma série de elementos estejam presentes. $\mathrm{O}$ assassinato precisa mobilizar um discurso reivindicatório que irá tanto apontar a injustiça daquela morte quanto atribuir a culpa a um determinado indivíduo ou grupo e conclamar que a agressão seja retaliada. Esse discurso reivindicatório articulado em torno do homicídio inicial terá que encontrar interlocutores que não somente tenham laços afetivos com a vítima, mas, principalmente, compartilhem dos valores, normas e sociabilidades favoráveis à retaliação privada e violenta, códigos e práticas que têm interseção com o chamado mundo do crime.

\section{Notas}

1 O presente trabalho foi realizado com apoio do Conselho Nacional de Desenvolvimento Científico e Tecnológico (CNPq), processo oㅜ 155501/2018-6, referente a bolsa de pós-doutorado júnior (PDJ).

${ }^{2}$ A expressão "mundo do crime" se refere a "o conjunto de códigos sociais, sociabilidades, relações objetivas e discursivas que se estabelecem, prioritariamente no âmbito local, em torno dos negócios ilícitos do narcotráfico, dos roubos, assaltos e furtos" (FELTRAN, 2011, p. 19). Já a categoria "do crime" se refere a um indivíduo inserido neste conjunto de práticas que internalizou seus códigos sociais e relações.

${ }^{3}$ O Programa de Controle de Homicídios - Fica Vivo!, parte da política de prevenção à criminalidade de Minas Gerais.

${ }^{4}$ Trecho retirado de meu caderno de notas durante o período de atuação no Programa de Controle de Homicídios - Fica Vivo!, no aglomerado Santa Lúcia, entre 2008 e 2011.

${ }^{5}$ Ver nota anterior.

${ }^{6} \mathrm{O}$ "vacilo" é uma vasta categoria que inclui as seguintes práticas: delatar para a polícia, cometer roubos dentro do bairro, acumular dívidas e, de forma geral, não honrar com sua palavra. Logo, no contexto das práticas criminosas, o "vacilão" é aquele em quem não se pode confiar, que deixa falhas e coloca em risco os outros envolvidos com o crime.

${ }^{7}$ A figura do noiado ou noia é, em geral, utilizada não para categorizar todos os usuários de drogas, mas sim aqueles usuários que são percebidos como indivíduos que perderam sua autonomia para o vício. É, portanto, muito associada, embora não exclusivamente, aos usuários de crack. O noiado é alvo de um discurso moral que, não raro, o reduz de indivíduo a coisa.

${ }^{8}$ Nesse caso, a categoria "trabalhador" ou "estudante" vai além do vínculo com o trabalho formal ou com a escola. A identidade pública de trabalhador é aplicada àqueles que se relacionam positivamente com a esfera do trabalho ou do estudo e negativamente com a esfera do crime.

9 'Sobre o processo de desumanização do noia e sua transformação em "coisa", ver Rui (2014).

${ }^{10}$ A letra inteira é a seguinte (grifos meus): "Covardia não enriquece o sistema/Ostentação é luxo mas não é nosso lema/Mulher dos outros não mexe que é problema/Adoradores da mancada o bonde não tem pena/Na vida errada você tem que andar certo/De vez em quando você vê a morte de perto/O verdadeiro guerreiro sempre anda esperto/Vê tudo mas nada vê, é surdo, mudo e cego/Errado está quem pratica o errado/Respeito é dado só por quem é respeitado/Muita cautela é melhor tomar cuidado/Entrar no caminho dos outros não é recomendado/Liberto está quem vive a liberdade/Humilde é quem pratica a humildade/O que acontece com aquele que vive na falsidade/Rala com a cara no chão aqui é sem massagem". Disponível em: Disponível em: https:/www.ouvirmusica.com.br/mc-orelha/1904906/

${ }^{11}$ É importante ressaltar que essa narrativa tem que ser considerada legítima para os atores do mundo do crime de forma relativamente uniforme. No duplo homicídio de Marli e sua filha, essa narrativa não foi considerada legítima. Tudo indica que os autores do crime só não foram mortos em retaliação por terem fugido do bairro e sido presos.

${ }^{12}$ Marques (2014) aborda a noção do "proceder" como uma dizibilidade sobre o sujeito, a possibilidade de dizer o que é certo ou errado no crime.

${ }^{13}$ Uma evidência neste sentido é o fato de que, das 158 situações de homicídios ocorridas nos três bairros entre 2010 e 2014 que compõem a amostra desta pesquisa, apenas 11 foram noticiadas em jornais ou noticiários de Belo Horizonte. 


\section{Referências}

BATELLA, Wagner Barbosa; DINIZ, Alexandre Magno Alvez. "Análise espacial dos condicionantes da criminalidade violenta no estado de Minas Gerais”. Sociedade \& Natureza, vol. 22, n. 1, pp. 151-163, 2010.

BLACK, Donald. "Crime as Social Control”. American Sociological Review, vol. 48, n. 1, pp. 3445, 1983.

BOLTANSKI, Luc; THÉVENOT, Laurent. “The Sociology of Critical Capacity”. European Journal of Social Theory, vol. 2, n. 3, pp. 359-377, 1999.

DAS, Veena; POOLE, Deborah. "State and its Margins: Comparative Ethnographies". In: DAS, Veena; POOLE, Deborah (orgs). Anthropology in the Margins of the State. Santa Fe: School of American Research Press, 2004, pp. 3-33.

DINIZ, Alexandre Magno Alves; LACERDA, Elisângela Gonçalves. “Análise exploratória dos homicídios entre jovens de 15 a 24 anos na Região Metropolitana de Belo Horizonte e seu Colar, entre 1999 e 2006". Revista Biologia e Ciências da Terra, vol. 10, n. 1, pp. 151-163, 2010.

FELTRAN, Gabriel de Santis. Fronteiras de tensão: Política e violência nas periferias de São Paulo. São Paulo: Editora Unesp, 2011.

MARQUES, Adalton. Crime e proceder: Um experimento antropológico. São Paulo: Alameda, 2014.

MISSE, Michel; WERNECK, Alexandre. "O interesse no conflito". In: MISSE, Michel; WERNECK, Alexandre (orgs). Conflitos de (grande) interesse: Estudos sobre crimes, violências e outras disputas conflituosas. Rio de Janeiro: Garamond, 2012, pp. 7-25.

ROCHA, Rafael Lacerda Silveira. "A guerra como forma de relação: Uma análise das rivalidades violentas entre gangues em um aglomerado de Belo Horizonte". Dilemas, Rev. Estud. Conflito Controle Soc., Rio de Janeiro, vol. 8, n. 2, pp. 277-301, 2015.

ROCHA, Rafael Lacerda Silveira. Vinganças, guerras e retaliações: Um estudo sobre o conteúdo moral dos homicídios de caráter retaliatório nas periferias de Belo Horizonte. Tese (Doutorado em Sociologia) - Universidade Federal de Minas Gerais, Belo Horizonte, 2017.

RUI, Taniele. Nas tramas do crack: Etnografia da abjeção. São Paulo: Terceiro Nome, 2014.

WEBER, Max. A objetividade do conhecimento nas ciências sociais. São Paulo: Ática, 2006.

ZILLI, Luís Felipe. Violência e criminalidade em vilas e favelas dos grandes centros urbanos: Um estudo de caso da Pedreira Prado Lopes. Dissertação (Mestrado em Sociologia) Universidade Federal de Minas Gerais, Belo Horizonte, 2004.

ZILLI, Luís Felipe. O bonde tá formado: Gangues, ambiente urbano e criminalidade violenta. Tese (Doutorado em Sociologia) - Universidade Federal de Minas Gerais, Belo Horizonte, 2011. 
RAFAEL LACERDA SILVEIRA ROCHA (rafael.rocha@crisp.ufmg.br) é pesquisador do Instituto Sou da Paz e bolsista de pósdoutorado do Centro de Estudos de Criminalidade e Segurança Pública (Crisp), da Universidade Federal de Minas Gerais (UFMG, Belo Horizonte, Brasil). É doutor e mestre em pelo Programa de Pós-Graduação em Sociologia (PPGS) da UFMG e tem graduação em ciências sociais pela mesma universidade.

D https://orcid.org/0000-0003-3587-0906

Recebido em: 07/02/2019

Aprovado em: 17/09/2019 